\title{
Adaptation from Conventional to Virtual Teaching Practices during COVID-19 Emergence: Perceptions of Multidisciplinary Teaching Faculty of Pakistan
}

\author{
Ume Hani ${ }^{10}$ Asma Saher Ansari10 Shujah Adil Khan ${ }^{2(0)}$ Misbah Ashraf Moten ${ }^{10}$ \\ Farzeen S. Waseem ${ }^{1 \odot}$ Zohaib Khurshid Sultan ${ }^{3}$
}

1 Department of Oral Biology, Dr. Ishrat-ul-Ebad Khan Institute of Oral Health Sciences, Dow University of Health Sciences, Karachi, Pakistan

${ }^{2}$ Department of Prosthodontics, Liaquat College of Medicine and Dentistry, Karachi, Pakistan

3 Department of Prosthodontics and Dental Implantology, College of Dentistry, King Faisal University, Al-Ahsa, Saudi Arabia

Address for correspondence Ume Hani, BDS, Department of Oral Biology, Dr. Ishrat-ul-Ebad Khan Institute of Oral Health Sciences, Dow University of Health Sciences, Ojha Campus, Scheme 33, Suparco Road, Karachi 75270, Pakistan (e-mail: ume.hani@duhs.edu.pk).

Eur J Gen Dent 2022;11:51-57.

\begin{abstract}
Objectives The perceptions maintained by the teaching profession have a plausible influence on the effectiveness of online teaching practices, but they have not been well comprehended in many institutions in Pakistan. This study is the first to demonstrate how different academic disciplines address the challenges and opportunities regarding online teaching during coronavirus disease 2019 (COVID-19) and whether there exists a strong correlation between respondents' attitudes and their field of discipline.

Materials and Methods A multi-centric cross-sectional survey was conducted online, and data gathered from the online survey were analyzed using SPSS version 16 , demographic and categorical data were analyzed in frequencies and percentages. A relationship between the attitudes of teachers with their areas of discipline and a difference in response between genders and age groups were analyzed using a chisquare test.

Results The findings of our study provide valuable understandings that most of the higher education faculty felt positively $(64.1 \%)$ regarding the online mode of teaching. However, their perceived attitudes have a significant influence on the nature of their academic discipline.

Conclusion These findings provide relevant suggestions to the core aspects of the use

Keywords

- online teaching

- faculty

- COVID-19 of the e-learning system during the COVID-19 pandemic to foster positive teaching experiences. The administrations and institutions can use it to identify the e-learning constraints within multiple fields of profession and help instructors generate quality materials that will reshape the framework of online education and preserve the practice of blended teaching even after the pandemic.
\end{abstract}

DOI https://doi.org/ 10.1055/s-0042-1742359. ISSN 2320-4753. (c) 2022. The Author(s).

This is an open access article published by Thieme under the terms of the Creative Commons Attribution License, permitting unrestricted use, distribution, and reproduction so long as the original work is properly cited. (https://creativecommons.org/licenses/by/4.0/)

Thieme Medical and Scientific Publishers Pvt. Ltd., A-12, 2nd Floor, Sector 2, Noida-201301 UP, India 


\section{Introduction}

With the advancement of emerging technology and improved internet facilities, the education program is experiencing a significant shift, education enabled by this technology is widely recognized as e-learning. ${ }^{1}$ With live lessons, whiteboards, downloadable slide sets, and discussion groups, virtual teaching is the way of live teaching, which is an automation of an established teacher-centered approach to education. ${ }^{2}$ Education is no longer confined to a conventional method; modern technological advancements (i.e., computers and the web) made it easier to deliver and attain knowledge residing anywhere around the world. ${ }^{3}$ Online education is playing an important role to improve the performance of academia; with technological developments, professional learning approaches usually concentrate on how individual applications and platforms can be used, but there seems to be a difference in teachers' attitudes and roles in an online setting than a campus setting, which is important to assess. ${ }^{4}$ Teachers in a virtual setting mostly provide online syllabi and materials, virtual communication tools, and devise a way to assess and evaluate students' learning progress and grades. ${ }^{5}$ Owing to the outbreak of coronavirus 2019 (COVID-19), the closure of the educational institutions had an unparalleled effect on education, teachers were advised to teach through online learning platforms during the lockdown which meant focusing on adapting to the virtual way of teaching. 6

Evolution of Online Teaching and Attitudes of Teachers Since previously known, teachers' attitudes and beliefs are critical because they are the primary leaders of computer technology integration into students' academics and can play an engaging ground for the students in a virtual setting. ${ }^{7}$ Because of the recent literature regarding the attitudes of teaching faculty, most high school teachers held a positive willingness to information and communication technology (ICT)/internet-based learning; however, the university teaching staff seemed to have an average level of selfperception toward internet-based education and they should be encouraged more. It has been reported that it is both comprehensive and inconclusive to really judge the efficacy of online education and also that the academic results of online and face-to-face courses do not vary statistically or functionally. ${ }^{8}$ In 2003, 57\% of educational leaders rated online education's learning outcomes as the same or better than those of face-to-face classroom learning, and this figure rose to $77 \%$ in $2012 .{ }^{9}$

\section{Success and Limitations of Online Teaching}

The implementation of e-learning provides institutions and learners with a great deal of flexibility in terms of time and place of delivery of education. ${ }^{10}$ Also, in terms of costeffectiveness, online education was found to be cost-effective than traditional face-to-face learning saving for accommodation costs, tuitions, and commuting. ${ }^{11}$ Learners are required to engage critically with the online sea of information that effectively induces in-depth learning instead of just surface learning and helps to really curb the gap between theory and practice because of the availability of online facilities. ${ }^{12}$ With technologies, however, also come certain obstacles and merely the presence of technology does not mean success. A recent study reported that the faculty suggested strong demand for more elaborative coaching for digital teachings, such as the creation of online courses, the evaluation of student performance, and the management of virtual classrooms. ${ }^{13}$ The more challenging limitation is the lack of in-person learning, often crucial for a student in need of help or moral support from the instructors, also factors affecting learning interest of students, keeping up with classroom decorum, participations, and discussion online. $^{14,15}$

\section{Online Teaching across Academic Disciplines}

The preparation of teachers for digital education is seldom evaluated in relation to academic disciplines. A recent study evaluated the views of education and engineering faculty on the importance of online programs and their support strategies. Their findings indicated a substantial difference implying that perceptions are subject specific. ${ }^{16}$ In Australian teacher education systems, academics tackling the implementation of online arts coursework were studied, and it probed visibility into how arts teachers are navigating the challenges and possibilities toward virtual education. ${ }^{17}$

\section{Impact of COVID-19 on Pakistan's Educational Sector} Technology-based education programs were described by the Ministry of Education and Federal Training (Pakistan, 2020) to assist learners via television, radio, online applications like Zoom, Google Classroom, and Microsoft Teams accessible through the internet, which means, academic readiness should be matched with the curriculum's length and the teaching speed is a successful parameter which should align with the student's ability to understand over the screen. Also, the technical support for student's feedback would ensure the efficacy of teaching online and highquality participation during the online sessions. ${ }^{18}$ The major challenges of e-learning systems in developing countries like Pakistan are the lack of ICT expertise, poor network infrastructure, and deficiency in content creation. ${ }^{19}$ The curriculum of distance learning should be well-designed, and the instructors should be dedicated and qualified with the skill set for virtual classroom tutoring. ${ }^{20}$ But the current situation is rather different, during these trying times of the global pandemic, the focus is not whether online teaching strategies can provide quality education, instead how academic institutions can adopt online learning in such a massive way. Recent studies have been conducted centered more around the perception of Pakistani students during COVID-19; more than 30\% of Pakistanis showed signs of dissatisfaction with lock-down distance courses in the crisis of pandemic. ${ }^{21}$ Most students felt that traditional classes were more efficient than online learning, and also both medical students and teachers believed that during the lockdown, online learning approaches facilitated student centeredness. ${ }^{22,23}$ 
The perceptions maintained by the teaching profession have a plausible influence on the effectiveness of online teaching practices, but they have not been well comprehended in many institutions. The research gap, which has been identified by extensive literature review, remains that in a developing nation like Pakistan, there is a compelling need to explore the perceptions of teachers toward online teaching practices to get better acquainted with the main areas of virtual advancement. As such, this study seeks to contribute to an understanding of how the academic disciplines address the challenges and opportunities regarding online education and their level of satisfaction which will be constructive in producing a more desirable online framework and help reshape education in times of global pandemic.

\section{Material and Methods}

\section{Study Design and Data Collection}

The study is quantitative and cross-sectional, as data collection was performed within a reasonably short time frame and at a point when most of the institutes were part of online learning platforms. A previously reported questionnaire was taken through consent via e-mail and was further modified over Google forms and sent via WhatsApp and e-mail. To meet the purpose of our study 20 questions were assembled across a five-points Likert scale. Before applying statistical tests, the responses of participants based on the Likert scale (1-strongly agree, 2-agree, 3-neutral, 4-disagree, and 5strongly disagree) were computed into a total score of responses, suggesting that lowest through 50 would mean positive and above 50 would mean negative. The employed questionnaire was piloted to ensure correctness and further validated using Cronbach's alpha to assess the questionnaire's reliability which was 0.717 , suggesting appropriation. An online open-epi calculator version 3 was used for study sample calculation keeping in mind the $86 \%$ response. ${ }^{24}$ At a $95 \%$ confidence interval and $80 \%$ power of test, a sample size of 185 respondents was calculated. The survey form was inclusive of an electronic consent along with demographic and specialty details of the participants and, further, concentrated on questions that led to the research objectives like the significant aspects of the online teaching system as well as the success and challenges during the COVID-19 pandemic.

\section{Context and Sample of Study}

A multi-centric study was conducted, inclusive of Karachi's public and private higher educational institutes and the participating teachers varied in their academic disciplines. These online educators were related to medical and dental, business, engineering, arts and textile, visual arts, and psychology. All the respondents had willingly consented to participate and were actively involved in online and distance teaching practices or had just recently experienced teaching online. Administrative staff and part-time faculty members and postgraduate trainees were exempted from the study.

\section{Statistical Analysis}

The data gathered from the online survey were analyzed using SPSS version 16. Keeping the objective of the study in mind, the data were then analyzed by percentages of teachers' responses suggesting a positive or a negative attitude. Demographic and categorical data were analyzed in frequencies and percentages. A relationship between the attitudes of teachers and their areas of discipline and a difference in response between genders and age groups were analyzed using the chi-square test, and a value of $p$ less than or equal to 0.05 was considered significant.

\section{Results}

\section{Profile of Respondents}

A total of 192 teaching staff responded to the questionnaire survey and were grouped according to their areas of discipline. The survey predominantly included females $(57.8 \%$ $[n=111])$ than males $(42.2 \%[n=81])$, and most of the teaching staff $(66.1 \%$ [ $n=127])$ were less than 35 years of age and $33.9 \%(n=65)$ were aged 35 years and above. Out of the total profile, $58.3 \%(n=112)$ belonged to medical discipline, 33.3\% $(n=64)$ were related to arts and business category, and $8.3 \%(n=16)$ of participants belonged to engineering universities. - Table 1 shows the demographic details of the respondents.

\section{Faculty Perceptions toward Online Teaching}

After the questionnaires' responses were coded for a complete analysis of results, it was concluded that most teachers (64.1\%) voiced a positive perception about online teaching practices. Most teachers considered that online education is a more accessible teaching method in terms of its flexibility. But the negative response (35.9\%) is also quite significant, indicating that the sudden transition from the physical classroom to virtual system alongside technical hurdles has been somewhat challenging for the teaching faculty, shown in - Fig. 1.

- Table 2 presents a descriptive analysis of the responses and their mean score. It can be gathered from these results that the higher education faculty was positive that online education can be served as a valuable tool $(M=2.32)$, requires well-prepared online lessons $(M=1.79)$, and demands institutional support for teacher training $(M=1.84)$. Furthermore, they were favorable to

Table 1 Demographic description

\begin{tabular}{|l|l|l|l|}
\hline Demographic & Value & Frequency $^{\mathrm{a}}$ & $\%$ \\
\hline \multirow{3}{*}{ Gender } & Male & 81 & $42.2 \%$ \\
\cline { 2 - 4 } & Female & 111 & $57.8 \%$ \\
\hline \multirow{3}{*}{ Age } & $<35$ & 127 & $66.1 \%$ \\
\cline { 2 - 4 } & $\geq 35$ & 65 & $33.9 \%$ \\
\hline \multirow{3}{*}{ Discipline } & Medical/Dental & 112 & $58.3 \%$ \\
\cline { 2 - 4 } & Arts/Business & 64 & $33.3 \%$ \\
\cline { 2 - 4 } & Engineering & 16 & $8.3 \%$ \\
\hline
\end{tabular}

${ }^{\mathrm{a} D e s c r i p t i v e ~ s t a t i s t i c s . ~}$ 


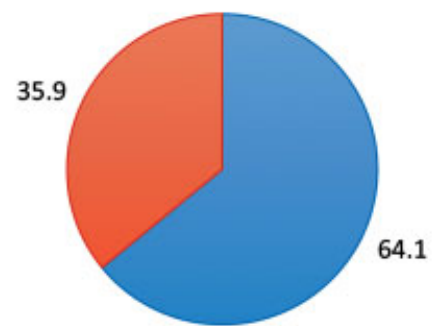

口 Positive $\square$ Negative

Fig. 1 Faculty perceptions toward online teaching. some opportunities of online teaching like the flexible and accessible method of teaching $(M=2.34)$, more technological awareness $(M=1.90)$, and offers to follow the personalized method of teaching $(M=2.27)$. However, when asked if virtual teaching practice is an effective method, the results were reasonably neutral with a leaning toward disagreement $(M=3.19)$. The responses also showed that the teachers were challenged by internet connectivity issues $(M=1.64)$, lack of face-to-face interaction with students $(M=1.58)$, difficulty with students' evaluation $(M=1.56)$, as well as the stresses and demands of online teaching $(M=2.36)$. The majority of the faculty suggested disagreement that online teaching improves student participation $(M=3.60)$ and that e-teaching saves the effort of teachers $(M=3.33)$.

Table 2 Summary statistics of faculty response

\begin{tabular}{|c|c|c|c|c|c|c|}
\hline Variable & $\begin{array}{l}\text { Strongly } \\
\text { agree, } \\
n(\%)\end{array}$ & $\begin{array}{l}\text { Agree, } \\
n(\%)\end{array}$ & $\begin{array}{l}\text { Neutral, } \\
n(\%)\end{array}$ & $\begin{array}{l}\text { Disagree, } \\
n(\%)\end{array}$ & $\begin{array}{l}\text { Strongly } \\
\text { disagree, } \\
n(\%)\end{array}$ & Mean \\
\hline E-teaching as a useful tool in education & $31(16.1)$ & $96(50)$ & $38(19.8)$ & $26(13.5)$ & $1(0.5)$ & 2.32 \\
\hline $\begin{array}{l}\text { The use of education technologies serves to } \\
\text { provide rich education experiences }\end{array}$ & $33(17.2)$ & $71(37)$ & $55(28.6)$ & $29(15.1)$ & $4(2.1)$ & 2.48 \\
\hline Online teaching provides extensive education & $15(7.8)$ & $37(19.3)$ & $58(30.2)$ & 67 (34.9) & $15(7.8)$ & 3.16 \\
\hline Online teaching improves student participation & $5(2.6)$ & $27(14.1)$ & $41(21.4)$ & $85(44.3)$ & $34(17.7)$ & 3.60 \\
\hline $\begin{array}{l}\text { Formal staff development for online teaching and } \\
\text { learning guidance should be facilitated }\end{array}$ & $65(33.9)$ & $105(54.7)$ & $14(7.3)$ & $4(2.1)$ & $4(2.1)$ & 1.84 \\
\hline Online teaching is an effective method of teaching & $11(5.7)$ & $49(25.5)$ & $46(24)$ & $64(33.3)$ & $22(11.5)$ & 3.19 \\
\hline E-teaching saves the effort of teachers & $14(7.3)$ & $49(25.5)$ & $28(14.6)$ & $61(31.8)$ & $40(20.8)$ & 3.33 \\
\hline $\begin{array}{l}\text { This method of teaching requires well-prepared } \\
\text { online teaching materials }\end{array}$ & $89(46.4)$ & $76(39.6)$ & $11(5.7)$ & $10(5.2)$ & $6(3.1)$ & 1.79 \\
\hline $\begin{array}{l}\text { The use of internet reduces the interest of students } \\
\text { for face-to-face activities }\end{array}$ & $47(24.5)$ & $91(47.4)$ & $28(14.6)$ & $25(13)$ & $1(0.5)$ & 2.18 \\
\hline $\begin{array}{l}\text { E-teaching may result in a decline of students' } \\
\text { performance overall }\end{array}$ & $64(33.3)$ & $65(33.9)$ & $47(24.5)$ & $14(7.3)$ & $2(1)$ & 2.09 \\
\hline $\begin{array}{l}\text { Online teaching is a more flexible and easier to } \\
\text { access way }\end{array}$ & $41(21.4)$ & $81(42.2)$ & $40(20.8)$ & $23(12)$ & $7(3.6)$ & 2.34 \\
\hline $\begin{array}{l}\text { This method of teaching is safer and reduces the } \\
\text { risk of contracting COVID-19 }\end{array}$ & $104(54.2)$ & $73(38)$ & $11(5.7)$ & $3(1.6)$ & $1(0.5)$ & 1.56 \\
\hline Online teaching saves time & $48(25)$ & $57(29.7)$ & $35(18.2)$ & $29(15.1)$ & $23(12)$ & 2.59 \\
\hline $\begin{array}{l}\text { Conducting online classes has made you more } \\
\text { technologically aware }\end{array}$ & $60(31.3)$ & $97(50.5)$ & $29(15.1)$ & $6(3.1)$ & $0(0)$ & 1.90 \\
\hline $\begin{array}{l}\text { Online teaching has enabled you to follow your } \\
\text { own personalized method of teaching }\end{array}$ & $49(25.5)$ & $81(42.2)$ & $34(17.7)$ & $17(8.9)$ & $11(5.7)$ & 2.27 \\
\hline $\begin{array}{l}\text { Online teaching is affected by technical and } \\
\text { internet connectivity issues }\end{array}$ & $102(53.1)$ & 71 (37) & $6(3.1)$ & $13(6.8)$ & $0(0)$ & 1.64 \\
\hline $\begin{array}{l}\text { Lack of face-to-face interaction makes online } \\
\text { teaching challenging }\end{array}$ & 95 (49.5) & $85(44.3)$ & $9(4.7)$ & $3(1.6)$ & $0(0)$ & 1.58 \\
\hline $\begin{array}{l}\text { Evaluation of students through online teaching is } \\
\text { more difficult }\end{array}$ & $108(56.3)$ & $68(35.4)$ & $9(4.7)$ & $6(3.1)$ & $1(0.5)$ & 1.56 \\
\hline $\begin{array}{l}\text { Online teaching has limited the personal } \\
\text { confidentiality }\end{array}$ & $35(18.2)$ & $83(43.2)$ & $50(26)$ & $22(11.5)$ & $2(1)$ & 2.34 \\
\hline $\begin{array}{l}\text { E-teaching is more stressful and demanding than } \\
\text { conventional teaching }\end{array}$ & 42 (21.9) & $85(44.3)$ & $28(14.6)$ & $27(14.1)$ & $10(5.2)$ & 2.36 \\
\hline
\end{tabular}




\section{Association between Faculty's Demographic Profile and Attitude}

The analyses for the significance level of $\alpha$ less than 0.05 were performed to check if the perceptions concerning various aspects of online teaching were linked to the participants' age and gender and their differences in academic disciplines. - Table 3 provides the attitudes of respondents toward online teaching when data are categorized as per their age, gender, and field of study. The analysis of the data reveals that the male and female respondents do not significantly differ in their attitudes ( $p$-value 0.56). Similarly, no substantial difference was found between their differences of age ( $p$-value 0.45$)$. However, it has been identified that faculty members concerning the discipline of medical sciences and engineering were more optimistic about e-teaching ( $p$-value 0.0003 ) as compared with those belonging to the business, arts, media, and alike as shown in -Table 3.

\section{Discussion}

In a time of global uncertainty, there is an urgency to ensure that our students' education will progress in the wake of COVID-19. The present study delved into faculty perceptions and experiences during a considerable paradigm shift in the field of education. The overall positive attitudes toward online teaching practices could be attributed to the fact that most of the teachers look at online education as a more accessible teaching method, especially in terms of its flexibility. This finding is similar to other research studies, where most teachers see online teaching as a convenient modality. ${ }^{24,25}$ Online mode of flexible learning has been addressed in the literature, as being more student centered and providing more accessible options with a great deal of flexibility to institutions in terms of time and place in the provision of lectures/lessons. ${ }^{10,26}$ However, internet connec-

Table 3 Influence of variables toward online teaching attitudes

\begin{tabular}{|c|c|c|c|}
\hline & & $\begin{array}{l}\text { Positive, } \\
n(\%)\end{array}$ & $\begin{array}{l}\text { Negative, } \\
n(\%)\end{array}$ \\
\hline \multirow[t]{4}{*}{ Gender } & Male & $50(61.7)$ & 31 (38.3) \\
\hline & Female & $73(65.8)$ & $38(34.2)$ \\
\hline & $p$-value & \multicolumn{2}{|l|}{$0.56^{\mathrm{a}}$} \\
\hline & Interpretation & \multicolumn{2}{|c|}{ Not significant } \\
\hline \multirow[t]{4}{*}{ Age } & $\leq 35$ & $79(62.2)$ & $48(37.8)$ \\
\hline & $>35$ & $44(67.7)$ & $21(32.3)$ \\
\hline & $p$-value & \multicolumn{2}{|l|}{$0.45^{\mathrm{a}}$} \\
\hline & Interpretation & \multicolumn{2}{|c|}{ Not significant } \\
\hline \multirow[t]{5}{*}{ Discipline } & Medical & $86(76.8)$ & $26(23.2)$ \\
\hline & Arts/Business & $24(37.5)$ & $40(62.5)$ \\
\hline & Engineering & $13(81.2)$ & $3(18.8)$ \\
\hline & $p$-Value & \multicolumn{2}{|l|}{$0.0003^{\mathrm{a}}$} \\
\hline & Interpretation & \multicolumn{2}{|l|}{ Significant } \\
\hline
\end{tabular}

${ }^{a} p$-Value calculated by using the chi-square test. tion and network issues have often severely impacted learning by online approaches. Unfortunately, teachers struggle with technological challenges all too often, rather than leveraging the relevant technologies to the most significant possible benefit of their learners, which hinders dramatically teachers' willingness to adopt e-learning practices. ${ }^{27}$ Similar responses were recorded in this study where teachers agree to the limitations of the internet and network connectivity issues. In the effort to allow online education to thrive, governments and institutions need to address the upgradation of IT departments and their services. The inaccessibility to technology is unfavorable when building a positive atmosphere for virtual instruction, regardless of a positive standpoint. ${ }^{28}$ Required software and durable internet access must be provided by the university administration, for universities to continually upgrade the necessary technical tools and also for user-friendly learning platform. ${ }^{29}$

The most agreed-upon response of this survey was that the lack of face-to-face interaction of the instructor with the learner and the apprehensions toward online evaluation and assessment. This resonates with the findings that a lack of feedback and interaction really cripples the quality of the online academic system. ${ }^{15} \mathrm{~A}$ more elaborate digital teaching coaching program which helps in the creation of online classes, student online evaluation, and management of virtual classrooms can settle these worries. ${ }^{13}$ While designing the online curriculum, composing a student assessment first would enable the teachers to keep in line with students' progress.

Another aspect the majority of faculty were positive about was that this new transition helped them to become wellversed with new teaching tools and software. A new learning curve with advanced technological experiences that were previously unrecognized to them and the comfort to customize the syllabus to devise strategies for establishing new and exciting content boosts motivation for effective education. ${ }^{30}$ By its very essence, e-learning applies new technology to both learner and educator, with the necessary skills and expertise needed for educational growth.

Despite the perceived attitudes, our research responses disclosed that online teaching is rather stressful and taxing for the more considerable part. The lack of prior involvement in the online course of instruction, the insufficient digital training of teachers, and the probable lack of institutional support may also have led directly to making this experience more complicated and stressful. ${ }^{30}$

This study also stressed that gender and age do not hold a significant co-relation was influencing teachers' attitudes toward virtual teaching practices, this is consistent with other research studies having no significant variations of these demographics. ${ }^{31}$ Yet, it has been reported that there exists a variation in discipline specificity toward the adaptation to online teaching. This aligns with the idea that differences in the nature of professions and faculty's beliefs are a dependable influence and reflect the quality of online content. ${ }^{16} \mathrm{~A}$ more positive attitudes of the medical and dental teaching faculty agree with many recent studies that online teaching provides easy administration and accessibility. ${ }^{23}$ Moreover, most lecturers were inspired by using online learning and prepared 
online learning courses for educational purposes. ${ }^{25}$ The positive-rated elements of online learning in medical, dental, and engineering professions were found to be greater student engagement, easier participation, and less time commitment. However, for teachers belonging to the profession of arts, design, architecture, and alike, online teaching seems to have clouded their pedagogical vision since the discipline requires constant fodder of critique and evaluation for students' growth. Our research data reveal that online arts education lacks to provide learners with a comprehensive learning experience and active student engagement. This is supported by the fact that virtual instruction has come off as a disembodied learning strategy, with reduced possibilities of actively enforcing methods and collective participation for online arts coursework, and that teacher training and support need to focus on positive teaching experiences within their areas of disciplines. ${ }^{32}$ To purpose it, all academic disciplines should be targeted equally to offer support, at an institutional level tailored to their educational needs, helping to implement successful online frameworks.

\section{Limitations}

The limitation of the current survey involves the procurement of an unequal amount of data from all the addressed disciplines of higher education, reflecting a small portion of the participants received. Also, the study was quantitative by nature, conducting a qualitative survey with in-depth interviews could yield additional conclusions. The results set out an understanding of the aspects leading to successes and drawbacks for online teaching modalities in Pakistan during COVID-19 concerning various academic disciplines, which is imperative, despite the limitations.

\section{Conclusions}

While the implementation of online teaching varied between institutions and their professions, this is the first study to reveal how the teaching faculty of Pakistan made deliberate attempts to address students' learning scenarios. For the effective execution of online learning across the disciplines, there is a need to acutely work in unison toward proposing an academic model where students can be virtually assisted without compromising the standards of their study programs. The findings of our study provide valuable insights that the majority of the higher education faculty were positive regarding the online mode of teaching. However, their perceived attitudes have a significant influence on the nature of their academic discipline. This study can be used by the administrations and institutions to identify the e-learning constraints within multiple fields of profession and help instructors to generate quality materials that will reshape the framework of online education along with preserving the practice of blended teaching even after the pandemic. It is a rigorous exercise that will require an excellent methodological and pedagogical problem-solving to create an online syllabus that is both productive and engaging.

\section{Recommendations}

In response to this study, it is recommended that further research into the implications and efficacy of online education on part of multidisciplinary teaching professions should be conducted. Also, for the cumulative improvement of online courses in a developing country like Pakistan, students' motivation should be enhanced by building a costeffective, user-friendly, and convenient online courses, universities should step up in building designated IT units with applications and tools having limited maintenance costs but supportive classroom instructions, and provisions should be made for technological support that targets each study discipline broadly and provides a surer ground for continuous professional development.

\section{Data Availability}

All data are available upon request to the corresponding author.

\section{Conflict of Interest}

None declared.

\section{Acknowledgments}

We acknowledge Ms. Hira Waseem, lecturer Biostatics, working at the School of Public Health, Dow University of Health Sciences, Karachi, Pakistan, for her contribution in the statistical work of this study.

\section{References}

1 Khogali SE, Davies DA, Donnan PT, et al. Integration of e-learning resources into a medical school curriculum. Med Teach 2011;33 (04):311-318

2 Torruam JT. Application of e-teaching and e-learning in Nigerian educational system. Int J Acad Res 2012;3(01):30

3 Strayer JF. How learning in an inverted classroom influences cooperation, innovation and task orientation. Learn Environ Res 2012;15(02):171-193

4 Guri-Rosenblit S. E-teaching in higher education: an essential prerequisite for e-learning. J New Approaches Educ Res. 2018;7 (02):93-97

5 Wilson BG, Ludwig-Hardman S, Thornam CL, Dunlap JC. Bounded community: designing and facilitating learning communities in formal courses. IRRODL 2004;5(03):1-22. Doi: 10.19173/irrodl. v5i3.204

6 Kapasia N, Paul P, Roy A, et al. Impact of lockdown on learning status of undergraduate and postgraduate students during COVID-19 pandemic in West Bengal, India. Child Youth Serv Rev 2020;116:105194

7 Gibson PA, Stringer K, Cotten SR, Simoni Z, O'neal LJ, HowellMoroney M. Changing teachers, changing students? The impact of a teacher-focused intervention on students' computer usage, attitudes, and anxiety. Comput Educ 2014;71:165-174

8 Rajab KD. The effectiveness and potential of E-learning in war zones: an empirical comparison of face-to-face and online education in Saudi Arabia. IEEE Access 2018; 6:6783-6794

9 Harish J. Online education: a revolution in the making. Cadmus. 2013;2(01):26

10 Smedley J. Modelling the impact of knowledge management using technology. OR Insight 2010;23(04):233-250 
11 Porter WW, Graham CR, Spring KA, Welch KR. Blended learning in higher education: Institutional adoption and implementation. Comput Educ 2014;75:185-195

12 Johns R. Application of web-based learning in teaching social work law. Soc Work Educ 2003;22(05):429-443

13 Dung D. The advantages and disadvantages of virtual learning. IOSR J Res Method Educ 2020;10(03):45-48

14 Chang C-L, Fang M. E-learning and online instructions of higher education during the 2019 novel coronavirus diseases (COVID19) epidemic. J Phys: Conf Ser 2020;1574(01):012166

15 Rios T. The relationship between students' personalities and their perception of online course experiences. J Educ Online. 2019;16(01): 1-11

16 Bolliger DU, Shepherd CE, Bryant HV. Faculty members' perceptions of online program community and their efforts to sustain it. Br J Educ Technol 2019;50(06):3283-3299

17 Burke K. Virtual praxis: constraints, approaches, and innovations of online creative arts teacher educators. Teach Teach Educ 2020; 95:103143

18 Chidambaram SMDN. Success of online teaching and learning in higher education-Covid 19 pandemic: a case study Valley View University, Ghana. Int J Appl Eng Res 2020;15(07):735-738

19 Aung TN, Khaing SS. Challenges of implementing e-learning in developing countries: a review. International Conference on Genetic and Evolutionary Computing 2015;2:405-11

20 Ali A, Ahmad I. Key factors for determining student satisfaction in distance learning courses: a study of Allama Iqbal Open University. Contemp Educ Technol 2011;2(02):118-134

21 Qazi A, Naseer K, Qazi J, et al. Conventional to online education during COVID-19 pandemic: do develop and underdeveloped nations cope alike. Child Youth Serv Rev 2020;119:105582

22 Adnan M, Anwar K. Online learning amid the COVID-19 pandemic: students' perspectives. J Pedagog Sociol Psychol. 2020;2(01): 45-51
23 Mukhtar K, Javed K, Arooj M, Sethi A. Advantages, limitations and recommendations for online learning during COVID-19 pandemic era. Pak J Med Sci 2020;36(COVID19-S4):S27-S31

24 Hoq MZ. E-Learning during the period of pandemic (COVID-19) in the kingdom of Saudi Arabia: an empirical study. Am J Educ Res 2020;8(07):457-464

25 Schlenz MA, Schmidt A, Wöstmann B, Krämer N, Schulz-Weidner $\mathrm{N}$. Students' and lecturers' perspective on the implementation of online learning in dental education due to SARS-CoV-2 (COVID19): a cross-sectional study. BMC Med Educ 2020;20(01):354

26 Zayapragassarazan Z. COVID-19: strategies for online engagement of remote learners. J Online Submission. 2020;9(273):1-18

27 Zounek J, Sudický P Heads in the cloud: pros and cons of online learning. International Conference DisCo New Technologies and Media Literacy Education, Prague. 2013:59-62

28 de la Rama JM, Sabases M, Antonion AF, et al. Virtual teaching as the 'new norm': analyzing science teachers' attitude toward online teaching, technological competence and access. Int J Adv Sci Technol 2020;29(07):12705-12715

29 Almaiah MA, Al-Khasawneh A, Althunibat A. Exploring the critical challenges and factors influencing the E-learning system usage during COVID-19 pandemic. Educ Inf Technol (Dordr) 2020; 25:1-20

30 Sepulveda-Escobar P, Morrison A. Online teaching placement during the COVID-19 pandemic in Chile: challenges and opportunities. Eur J Teach Educ 2020;43(04):587-607

31 Afzal HMI, Ishtiaq M, Ali R, Afzal S, Ahmad F, Junaid K, Younas S, Hamam SSM, Ejaz H. COVID-19 pandemic and e-learning system: perception of teaching faculty at medical colleges in Pakistan. Pak J Med Sci 2020;14(03):760-763

32 Howard SK, Tondeur J, Siddiq F, Scherer R. Ready, set, go! Profiling teachers' readiness for online teaching in secondary education. Technol Pedagogy Educ 2021;30(01):141-158 